\title{
Laser Science and its Applications in Prosthetic Rehabilitation
}

\author{
Revathy Gounder $^{1 *}$, Srinivasan Gounder ${ }^{2}$ \\ 'Department of Prosthodontics and Implant Dentistry, Saveetha Dental College and Hospital, Chennai, India \\ ${ }^{2}$ Department of Microbiology, A.C.S Medical College and Hospital, Chennai, India
}

*Correspondence to

Revathy Gounder, MDS; Saveetha

Dental College and Hospital,

162, Poonamallee High Road,

Chennai-600077, Tamil Nadu, India.

Tel: $+91-8682873804,+44-$

26801580-86;

Email: revathygounder@yahoo.com

Published online 27 October 2016

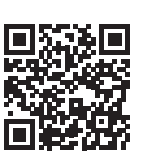

\begin{abstract}
The minimal invasive nature of lasers, with quick tissue response and healing has made them a very attractive technology in various fields of dentistry which serves as a tool to create a better result than ever before. The rapid development of lasers and their wavelengths with variety of applications on soft and hard tissues may continue to have major impact on the scope and practice in prosthetic dentistry. The purpose of this article is to make every clinician familiar with the fundamentals of lasers and different laser systems to incorporate into their clinical practices.

Keywords: Lasers; Prosthetic dentistry; Carbon dioxide laser; Er:YAG laser; Nd:YAG laser; Diode laser.
\end{abstract}

\section{Introduction}

A thorough knowledge regarding different lasers and its interaction within the target tissue of the oral cavity is essential to ensure optimal treatment results. ${ }^{1}$ Over the course of the past five decades, laser technology has made a niche market in the field of dentistry. The first laser, synthetic ruby laser was invented by Theodore Maiman ${ }^{2}$ in 1960. Golman et $\mathrm{al}^{3}$ and Stern and Sognnaes ${ }^{4}$ described the effect of ruby laser on dentin and enamel in 1964. In 1985, Myers and Myers modified an ophthalmic Neodymium- based laser (Nd:YAG) for dental use. ${ }^{5}$ This article reviews the role of lasers and its applications in the field of removable and fixed prosthetic dentistry.

\section{Physical Science}

An acronym "LASER" stands for "Light Amplification by Stimulated Emission of Radiation." Spontaneous emission, Stimulated emission, and Absorption are the three different phenomenon which occurs during the formation of an atomic spectral line described by Albert Einstein in $1916 .{ }^{6}$ LASER is a monochromatic and coherent light which is produced by the release of more photons which triggers chain reaction. The laser compartment consists of six major components (Figure 1); which is important to understand for the production of light. ${ }^{7}$

Active Medium: It is an optical cavity consists of chemical compounds or substances, molecules at the centre.

Pumping Mechanism: Optical cavity is surrounded by pumping unit which is either a arc light or a flash light for excitation, or it can be an electromagnetic coil or diode unit.
Optical Resonators: They are usually a polished surfaces or two mirrors which are aligned at each end of the optical cavity. The function of the optical resonators are to perform amplification and collimation of the developing beam.

Cooling System: A heat is generated during the production of laser energy. So a cooling system is used to lower the temperature of the compartments.

Control Panel: Control panel is used to control variable parameters for the output of the laser.

Delivery System: It is a system through which laser reaches its targeted site. Examples are articulated arm, a handpiece, a flexible hollow wave guide or a quartz fibre-optic.

\section{Laser Interaction With Target Tissue}

Laser interacts with the target tissue in four different ways, depending upon the optical properties (Figure 2). ${ }^{8}$ Absorption: Laser wavelength, pigmentation of the tissue,

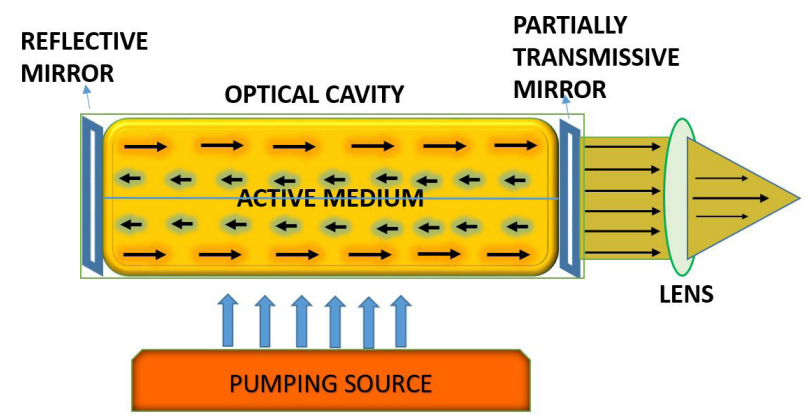

Figure 1. Basic Components of a Laser. 


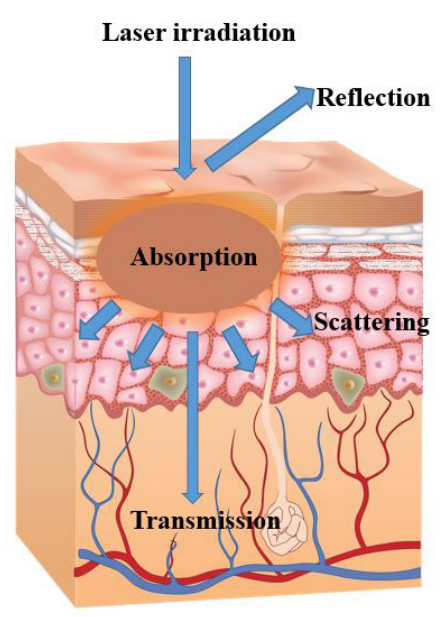

LASER TISSUE EFFECT

Figure 2. Laser Interaction With Tissue.

amount of water present in the tissue, emission mode of the laser are the major constituents based on which the tissue absorbs the total amount of energy. Longer wavelengths are less readily absorbed than the shorter wavelengths (500-1000 nm) in pigmented tissue and blood elements.

Transmission: Transmission is the direct passage of the laser energy through the target tissue without any effect, the inverse of absorption. It is highly based on the wavelength of the laser light.

Reflection: The third effect is reflection, in which the laser beam bounces off the target surface with no effect. A caries detector is used to measure the degree of sound structure of the tooth.

Scattering: Unwanted tissue injury could occur, if heat is transmitted to the tissue through scattering at the surgical site.

\section{Laser Energy and Tissue Temperature}

When the tissue is exposed to the temperature above normal, the initial phase hypothermia occurs, but the tissue is not destroyed. Denaturation and co-agulation of the protein occurs approximately at $60^{\circ} \mathrm{C}$. The clinical practitioner can remove the granulomatous lesion by utilizing the laser parameters within the temperature range, without vaporization of the surrounding tissue. Adherence of the tissue layers occurs at $70^{\circ} \mathrm{C}$ to $80^{\circ} \mathrm{C}$. At $100^{\circ} \mathrm{C}$, vaporization of the water within the tissue occurs. The ablation starts at this temp but the dental tooth structures will not be ablated. At about $200^{\circ} \mathrm{C}$, dehydration is complete and the tissue carbonizes (Figure 3). Continuous application of laser produces carbonisation of the tissue which prevents normal tissue ablation, causing tissue necrosis. ${ }^{9,10}$

\section{Classification of Lasers}

According to the wavelength ${ }^{11}$ :

- The ultraviolet spectrum range (approximately below $400 \mathrm{~nm}$ ).

- $\quad$ The visible spectrum range (approximately 400-700 $\mathrm{nm})$.
- $\quad$ The infrared spectrum range (approximately $700 \mathrm{~nm}$ to the microwave spectrum).

Wavelength from ultraviolet to the far infrared range are generally used in medical practice which ranges from 193 $\mathrm{nm}$ to $1060 \mathrm{~nm}$ (Figure 4 ).

\section{Use of Lasers in Prosthetic Dentistry}

Dentists can choose from a variety of wavelengths to use in the oral cavity. A complete understanding of the interaction between each of these different laser wavelengths and the target tissues is essential to ensure optimal treatment results.

\section{Removable Prosthetics}

Treatment of unsuitable alveolar ridges: Ill fitting dentures due to reduced stress bearing area increases the load in the natural remaining tissue structures which is not totally treated by soft linings. Soft tissue lasers are now a days used to perform surgery to expose the hard tissue such as bone with various soft tissue wavelengths. $\left(\mathrm{CO}_{2}\right.$ laser, diode, neodymium-doped yttrium aluminium garnet [Nd:YAG]). Erbium lasers are usually performed for hard tissue treatment procedures. ${ }^{12}$

Exostoses or tori removal: It may cause a prosthetic complications, if they are enlarged or irregular in shape or the mucosal covering becomes ulcerated. These may interfere with the lingual extension or flanges of the mandibular prosthesis or palatal coverage of the maxillary prosthesis. erbium:yttrium-aluminum-garnet (Er:YAG) is the first

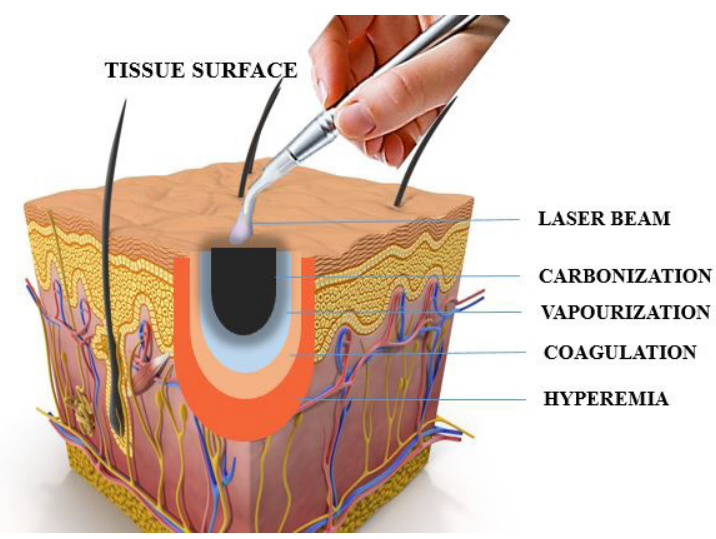

Figure 3. Laser Energy and Tissue Temperature.

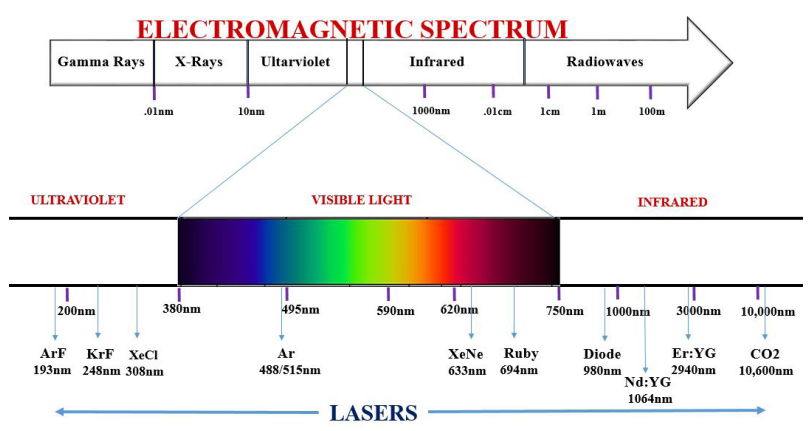

Figure 4. Electromagnetic Spectrum and Laser Wavelength. 
choice of treatment to excise the bony protuberances. The main advantage of the use of Er:YAG laser is the reduction of overheating, decontamination, biostimulation and the absence of the production of smear layer which interrupts with the healing process. ${ }^{13}$

- Fibroma: Fibrous tissue may be formed due to sharp denture flange or overcompression of posterior palatal seal area which causes persistent injury to the tissue. This can be treated with any of the soft tissue lasers which allows the tissue to re-epithelialize. Carbonization was easily removed using a cotton swab soaked with a Lotagen ${ }^{\circledR}$ (36\% dihydroxy dimethyl diphenylmethane- disulfonic polymerized) solution to ensure a rapid and better quality of healing. ${ }^{14}$

- Vesitbuloplasty: Vestibuloplasty is chosen when prosthetic stability is poor due to mandibular or maxillary crest atrophy and a small vestibule length. $\mathrm{CO}_{2}$ technology provides a simple and secure method. The sutures and grafts are not needed. Removable denture must be immediately and temporarily relined with soft acrylic. Patients should wear the denture for 3 to 4 weeks after surgery. ${ }^{15}$

- Frenectomy: The presence of high labial frenulum (median or laterals) may cause instability of the oral prosthetic structure and should be removed to increase the retention of the denture. A thin layer of a minimum of $1 \mathrm{~mm}$ of soft tissues should be kept to cover the maxillary bone up to the end of the vestibule. The insertion of the frenulum at the level of the lip should also be removed. Sutures were made only on the lip's side of the frenulum. ${ }^{12}$

- Epulis fissuratum: Epulis is the overgrowth of the mucosa in CD wearing patients, caused by the chronic irritation of the tissue. The most commonly used techniques for the excision of the lesion are soft tissue lasers, surgical or electrical scalpel. ${ }^{16}$

- Denture stomatitis: Denture stomatitis (DS) is a chronic candidal infection associated with $60 \%$ to $65 \%$ of denture wearers. Laser beam not only helps in ablation of superficial candida contaminated epithelial surface, but also prevents inflammation of adjacent normal mucosa. Postoperative prescription of antibiotics or non-steroidal anti-inflammatory drugs (NSAID) will not be required since the laser itself act as a virucidal and bactericidal. This may prevent the reinfection or secondary infection by bacteria. Lasers helps in adequate pain relief due to neuron sealing effect. $^{17}$

- To study the accuracy of impression and complete denture occlusion: The newly developed laser scanner is a $3 \mathrm{D}$ digitizer which tracks the co-ordinates from the specimen $(\mathrm{x}, \mathrm{y}, \mathrm{z})$ and stores the data with a resolution of $130 \mathrm{~mm}$ at $100 \mathrm{~mm}$. The 3D laser captures complex 3D texture-mapped models and they are exported into a 3D (Scan Surf) software application where it is built and triangulated into a 3D meshwork image of the object. ${ }^{18}$

- Denture fabrication: Denture fabrication is done by selective laser sintering (SLS). Laser fusion utilises a high power beam of $\mathrm{CO}_{2}$ laser which melts the polymer or metal powders at raised temperature. Thus, it builds the strong and most durable form of design from a digitized model which is stored as a standard triangulation language (STL) format. ${ }^{19}$

- Laser welding component of removable partial dentures: Nd:YAG laser is used for the prosthetic construction. With laser welding, 20\%-50\% higher values of tensile strength can be achieved in comparison with soldering. ${ }^{20}$

\section{Fixed Prosthetics}

- Crown lengthening: Lasers provides optimum operator control, finely traces the incision lines and precisely sculpts the gingival margin. For osseous crown lengthening, ${ }^{21}$ Erbium laser treatment shows minimal displacement of the tissue and isolated papillae is limited for flap preparation if necessary.

- Tooth preparation: Er:YAG laser is the treatment of choice for preparing dental hard tissues. In most instances, the Er:YAG laser numbs the tooth, so there is usually no need for anaesthetic. A high-speed handpiece may cause microfractures in the enamel, whereas there is no risk of microfracture with the laser. ${ }^{22}$

- Trough formation: Trough is created around the tooth structure before impression procedure. Which eliminates the need of retraction cord placement, electrocautery, and hemostatic agents. The laser provides efficient, predictable, no or minimal bleeding during the impression procedure, thus minimises the post-operative pain and chair time. ${ }^{23}$

- Laser phototherapy: Low-level laser therapy (LLLT) such as AsGaAl (gallium aluminum arsenide) 660 $\mathrm{nm}$ laser is used in the gingival sulcus, gingival tissue surrounding the crown preparation to promote soft tissue bio-modulation; so that no inflammation signals should be present in the gingival tissue before the final luting procedure. ${ }^{24}$

- Dentinal decontamination: High-level laser therapy (HLLT) is used as a last step before the final cementation of crown due to their better penetration into dentinal tissues and microbial inhibition properties. ${ }^{25-27}$

- Veneer removal: The laser energy transmits through the ceramic glass and is absorbed by the water molecules present in the adhesive. De-bonding occurs at the silane - resin interface. The technique takes approx. Two seconds to 2 minutes for ceramic restorations, based on the thickness of the ceramic restoration. ${ }^{28}$

- Bleaching: In-office bleaching treatments are commonly done by Ar and diode lasers. KTP laser and $\mathrm{H}_{2} \mathrm{O}_{2}$ gel combination (Smart Bleach gel [SBI]) is currently the only laser bleaching system with photothermal, photochemical and photocatalytic activity. Laser tooth whitening is to achieve the ultimate bleaching power while avoiding any adverse effects. ${ }^{29}$ - E model preparation: 3D laser scanner is a valuable 
Table 1. Standard IEC Classification

\begin{tabular}{ll}
\hline Class & Description \\
\hline I & Very low risk, "safe under reasonable foreseeable use" \\
I M & Wavelengths between $302.5 \mathrm{~nm}$ and $400.0 \mathrm{~nm}$ are safe except when used with optical aids (e.g. binoculars). \\
II & Wavelengths between $400 \mathrm{~nm}$ and $700 \mathrm{~nm}$. No known hazard with 0.25 seconds (aversion response). \\
II M & No known hazard with 0.25 seconds (aversion response) unless collecting optics are used. \\
III R & Direct intrabeam viewing is potentially hazardous but the risk is lower than Class III B lasers. \\
III B & $\begin{array}{l}\text { Normally hazardous under direct beam viewing conditions, but are normally safe when viewing diffuse reflections. } \\
\text { IV }\end{array} \quad \begin{array}{l}\text { Hazardous under both intra beam and diffuse reflection viewing conditions. They may also cause skin injuries and are } \\
\text { potential fire hazards. }\end{array}$ \\
\hline
\end{tabular}

tool for its ease of application and no need of cast preparation as e-models are prepared from scanned impressions. It consists of laser beam (visible light) and camera like device which employs the principles of triangulation. ${ }^{30}$

\section{Implantology}

- Second stage uncovering: $\mathrm{CO}_{2}$ laser and almost all types of lasers are used to remove overlying soft tissue. Immediate impression can be taken after second stage surgery due to minimal blood contamination and tissue shrinkage.

- Repair of ailing implant: LLLT such as diode soft laser $(690 \mathrm{~nm})$ are used on the contaminated surface for 60 seconds after the placement of toluidine blue O for 1 minute. It reduces the bacteria count by $92 \%$.

- Implant site preparation: The removal of the overlying structure at implant site leads to fast healing time, better integration, minimal patient discomfort, and more bone to implant contact. ${ }^{31}$

- Peri-implantitis: Diode laser, $\mathrm{CO}_{2}$ laser and Er:YAG laser can be used to remove granulated tissue at the inflammatory site and to decontaminate the implant surface. $^{32}$

\section{Aesthetic Dentistry}

- Smile design: Argon, $\mathrm{CO}_{2}$, diode, erbium, and pulsed $\mathrm{Nd}$ :YAG lasers are currently used for smile designing. Before using laser, soft tissues are marked with pencil for the determination of proper gingival contour, symmetry, axial inclination, and zenith. A periodontal probe is placed apically to the alveolar crest to measure the marginal gingiva. Biological width is determined and it is marked as the reference spot with laser allowing the clinician to focus on aesthetics and serving as the visual finishing point. ${ }^{33}$

\section{Maxillofacial Prosthodontics}

- 3D Printing: 3D printing for both bony and soft tissue reconstruction, has become the essential clinical tool which derives a model from a computer-aided design (CAD) built in a layer by layer fashion. Various $3 \mathrm{D}$ printing techniques have been explored in the clinical setting such as stereolithography, multijet modelling, SLS, binder jetting and fused deposition modelling. ${ }^{34,35}$

\section{Laser Hazard and its Safety Measures}

The output of certain lasers are vulnerable to human body and its exposure can cause injury to the eye and skin. Controlling the hazards depends on the limited access to the room and equipments, proper use of personal protective devices, monitoring the system, testing and operations of the laser and its delivery systems, correct applications, and vigilance on the part of each laser team member. ${ }^{36} \mathrm{~A}$ new system of classification by International Electrotechnical Commission (IEC), a global organization is set to indicate the level of laser beam hazard shown in Table $1 .{ }^{37}$

\section{Conclusion}

Laser offers shorter and painless procedure with minimal or no discomfort, thus less damage to the surrounding tissue. It is an effective and excellent method to be used in various applications ranging from soft tissues to hard tissues. The Clinical practitioner and the Dentists should be knowledgeable about the various systems of laser so that they can maximize the number of procedures in dental practices.

\section{Ethical Considerations}

Not applicable.

\section{Conflict of Interests}

None.

\section{References}

1. Convissar RA. The biologic rationale for the use of lasers in dentistry. Dent Clin North Am. 2004;48(4):771-794. doi:10.1016/j.cden.2004.06.004.

2. Maiman TH. Stimulated Optical Radiation in Ruby. Nature. 1960:187:493-494. doi:10.1038/187493a0.

3. Goldman L, Hornby P, Meyer R, Goldman B. Impact of the laser on dental caries. Nature. 1964;203:417.

4. Stern RH, Sognnaes RF. Laser beam effect on dental hard tissues (Abstract 307). J Dent Res. 1964;43:873.

5. Jyoti N, Pankaj M, Tulika G, Shelly A. Dental lasers - a boon to prosthodontics - a review. Int J Den Clin. 2010: 2(2):13-21.

6. Welch AJ, Torres JH, Cheong WF. Laser Physics and LaserTissue Interaction. Tex Heart Inst J. 1989;16(3):141-149.

7. Parker S. Introduction, history of lasers and laser light production. Br Dent J. 2007;202(1):21-31. doi:10.1038/ bdj.2006.113.

8. Gupta S. Lasers in dentistry - an overview. Trends Biomater 
Artif Organs. 2011;25(3):119-123.

9. Russel AD. Lethal effects of heat on bacterial physiology and structure. Sci Prog. 2003;86(1):115-137. doi:10.3184/003685003783238699.

10. Coluzzi DJ. Fundamentals of dental lasers, science and instruments. Dent Clin N Am. 2004;48:751-770. doi:10.1016/j.cden.2004.05.003.

11. Weber MJ. Handbook of Laser Wavelengths. New York: CRC Press; 1999.

12. Kesler G. Clinical applications of lasers during removable prosthetic reconstruction. Dent Clin N Am. 2004;48:963969. doi:10.1016/j.cden.2004.05.013.

13. Rocea JP. Er:YAG laser: a new technical approach to remove torus palatinus and torus mandibularis. Case Rep Dent. 2012;2012:487802. doi:10.1155/2012/487802.

14. Namour S. Atlas of Current Oral Laser Surgery. Boca Raton, FL: Universal Publishers; 2011.

15. Kumar R, Jain G, Dhodapkar SV, Kumathalli KI, Jaiswal G. The comparative evaluation of patient's satisfaction and comfort level by diode laser and scalpel in the management of mucogingival anomalies. J Clin Diagn Res. 2015;9(10):ZC56-ZC58. doi:10.7860/ JCDR/2015/14648.6659.

16. de Arruda Paes-Junior TJ, Cavalcanti SC, Nascimento $\mathrm{DF}$, et al. $\mathrm{CO} 2$ laser surgery and prosthetic management for the treatment of epulis fissuratum. ISRN Dent. 2011;2011:282361. doi:10.5402/2011/282361.

17. Keerthana S, Sivakumar P, Sudhakar R, Sankaranarayanan S. Denture Stomatitis. Treatment with diode laser. International Journal of Prosthodontics and Restorative Dentistry. 2011;1(1):55-57.

18. Sandesh G, Sanjay K, Rohit L, Shraddanand B, Shivaraj W. Lasers in Prosthodontics. Journal of Evolution of Medical and Dental Sciences. 2012;1(4):624-633.

19. Wu J, Gao B, Tan H, Chen J, Tang CY, Tsui CP. A feasibility study on laser rapid forming of a complete titanium denture base plate. Lasers Med Sci. 2010;25(3):309-315. doi:10.1007/s10103-008-0603-x

20. Carek A, Zivko-Babic J, Schauperl Z, Jakovac M. Macroscopic analysis of Co-Cr base alloys joints. Acta Stomatologica Croatica. 2007;41(3):216-224.

21. Dyer B. Minimally invasive osseous crown-lengthening procedure using an erbium laser: clinical case and procedure report. J Cos Dent. 2008; 23(4):72-78.

22. Fred M. Erbium laser. J Can Dent Assoc. 2004;70(5):334335.
23. Parker S. The use of lasers in fixed prosthodontics. Dent Clin N Am. 2004;48:971-998.

24. Cardoso Bezerra SJ, Fioranelli Vieira G, Eduardo Cde P, de Freitas PM, Aranha AC. Laser phototherapy $(660 \mathrm{~nm})$ can be beneficial for reducing gingival inflammation in prosthodontics. Case Rep Dent. 2015;2015:132656. doi:10.1155/2015/132656.

25. Pejcic A, Kojovic D, Kesic L, Obradovic R. The effects of low level laser irradiation on gingival inflammation. Photomed Laser Surg. 2010;28(1):69-74.

26. Ramalho KM, de Freitas PM, Correa-Aranha AC, BelloSilva MS, Lopes RM, Eduardo Cde P. Lasers in esthetic dentistry: soft tissue photobiomodulation, hard tissue decontamination and ceramic conditioning. Case Rep Dent. 2014;2014:927429.

27. Klinke T, Klimm W, Gutknecht N. Antibacterial effects of Nd: YAG laser irradiation within root canal dentin. J Clin Laser Med Surg. 1997;15(1):29-31.

28. Spitz SD. Lasers in prosthodontics: clinical realities of a dental laser in a prosthodontic practice. Alpha Omegan. 2008;101(4):188-194.

29. Roeland JG. The use of KTP laser, an added value for tooth bleaching. The Journal of Oral Laser Applications. 2009;9(4):219-226.

30. Güth JF, Keul C, Stimmelmayr M, Beuer F, Edelhoff D. Accuracy of digital models obtained by direct and indirect data capturing. Clin Oral Investig. 2013;17:1201-1208.

31. Romanos G. Current concepts in the use of lasers in periodontal and implant dentistry. J Indian Soc Periodontol. 2015;19(5):490-4. doi:10.4103/0972-124X.153471.

32. Martin E. Lasers in dental implantology. Dent Clin N Am. 2004;48:999-1015.

33. Adams TC, Pang PK. Lasers in aesthetic dentistry. Dent Clin N Am. 2004;48:833-860.

34. Tukuru N, Gowda KP, Ahmed SM, Badami S. Rapid prototype technique in medical field. Res J Pharm Tech. 2008;1(4):341-344.

35. Subburaj K, Nair C, Rajesh S, Meshram SM, Ravi B. Rapid development of auricular prosthesis using $\mathrm{CAD}$ and rapid prototyping technologies. Int J Oral Maxillofac Surg. 2007; 36(10):938-943.

36. Smalley PJ. Laser safety: risks, hazards, and control measures. Laser Ther. 2011;20(2):95-106. doi:10.5978/ islsm.20.95

37. Bargman H. Laser Classification Systems. J Clin Aesthet Dermatol. 2010;3(10):19-20. 